\title{
MÉTODOS PARA QUEBRA DE DORMÊNCIA DE UNIDADES DE DISPERSÃO DE Zizyphus joazeiro Mart. (RHAMNACEAE) ${ }^{1}$
}

Edna Ursulino Alves², Joel Martins Braga Júnior ${ }^{3}$, Riselane de Lucena Alcântara Bruno², Ademar Pereira de Oliveira ${ }^{2}$, Edson de Almeida Cardoso ${ }^{3}$, Adriana Ursulino Alves ${ }^{4}$, Anarlete Ursulino Alves ${ }^{4}$, Kelina

Bernardo Silva ${ }^{5}$

\begin{abstract}
RESUMO - O Z. joazeiro é uma espécie florestal de grande importância socioeconômica para a Região Nordeste do Brasil e apresenta dificuldades na germinação das unidades de dispersão, causada pela impermeabilidade à água. Este estudo avaliou tratamentos pré-germinativos de superação de dormência de unidades de dispersão de Z. joazeiro. O experimento foi conduzido em casa de vegetação, no Centro de Ciências Agrárias da Universidade Federal da Paraíba, em Areia, PB, Brasil. Os tratamentos consistiram em: testemunha (unidades de dispersão intactas), escarificação mecânica com lixa d'água, imersão em água, à temperatura ambiente, por 24, 48, 72, 96 e $120 \mathrm{~h}$, imersão em água à temperatura de $70^{\circ} \mathrm{C}$, por $3 \mathrm{~min}$, e imersão em ácido sulfúrico concentrado por 30,60, 90, 120 e $150 \mathrm{~min}$. As variáveis avaliadas foram porcentagem de emergência, primeira contagem e velocidade de emergência, comprimento e massa seca de plantas. Os tratamentos que propiciaram máxima emergência de plântulas de Z. joazeiro foram imersão de unidades de dispersão em água fria por $48 \mathrm{~h}$, imersão em água a $70{ }^{\circ} \mathrm{C}$ por 3 min e escarificação manual com lixa, por superar a dureza tegumentar das unidades de dispersão dessa espécie.
\end{abstract}

Palavras-chave: Juazeiro, emergência, vigor, espécie florestal e planta medicinal.

\section{METHODS FOR DORMANCY BREAKING OF Zizyphus joazeiro Mart. DISPERSAL UNITS}

\begin{abstract}
Z. joazeiro is a forest species of great socioeconomic importance for the Brazilian Northeast region, but of difficult germination caused by the water impermeability of dispersal units. The present study evaluated pre-germinative treatments for overcoming dormancy in Zizyphus joazeiro seeds. The experiment was carried out in greenhouse conditions at Centro de Ciencias Agrárias, Universidade Federal da Paraíba, Areia-PB, Brazil. The treatments were as follow: control (intact dispersal units), mechanical scarification with sandpaper, immersion in water at room temperature for 24, 48, 72, 96 and 120 hours, immersion in water at 70 C for three minutes and, immersion in concentrated sulfuric acid for 30, 60, 90, 120 and 150 minutes. The evaluated variables included emergence percentage, first count and emergence speed index, length and weight of plant dry matter. The treatments showing higher Z. joazeiro seedling emergence were immersion of dispersal units in cold water for 48 hours, immersion in water at 70 C for three minutes and manual scarification with sandpaper, overcoming tegument hardness in dispersal units of this species.
\end{abstract}

Keywords: Juazeiro, emergence, vigor, forest species and medicinal plant.

\footnotetext{
${ }^{1}$ Recebido em 23.03.2007 e aceito para publicação em 19.05.2008.

${ }^{2}$ Departamento de Fitotecnia. CCA-UFPB, Areia-PB. Cx. Postal 2, 58397-000 Areia-PB. E-mail : <ednaursulino@cca.ufpb.br> e<lane@cca.ufpb.br>.

${ }^{3}$ Graduação em Agronomia. CCA-UFPB, Areia-PB.

${ }^{4}$ Programa de Pós-Graduação em Agronomia da UNESP-Jaboticabal-SP. E-mail : <urlino@ hotmail.com>e <adusp@ hotmail.com> ${ }^{5}$ Programa de Pós-Graduação em Agronomia da UFPB, Areia-PB.
} 


\section{INTRODUÇÃO}

O juazeiro (Zizyphus joazeiro), pertencente à família Rhamnaceae, é uma árvore brasileira típica dos sertões nordestinos, sendo endêmica da Caatinga (PRADO e GIBBS, 2003). Ocorre do Piauí até o Norte de Minas Gerais, incluindo o polígono da seca nordestino (MATOS, 2000). A espécie apresenta grande potencial econômico e importância para a região semi-árida, sendo utilizada como ornamental (MENDES, 1996; LORENZI, 2002); na medicina popular, é muito empregada em tratamento de gastrites, gripes, contusões e ferimentos, na fabricação de cosméticos, xampus anticaspa e creme dental (MATOS, 2000), bem como na alimentação de animais, principalmente nos períodos de seca (MENDES, 1996).

Apesar da grande utilidade, a exploração do $Z$. joazeiro limita-se ao extrativismo, sendo necessários conhecimentos capazes de contribuir para a sua domesticação e cultivo. Conforme Carvalho e Nakagawa (2000), para que uma semente possa expressar sua máxima capacidade fisiológica é preciso que lhes sejam fornecidas uma série de condições ótimas, as quais já estão estabelecidas para um grande número de espécies. No entanto, as unidades de dispersão de Z. joazeiro apresentam-se com endocarpo duro e resistente, o que representa uma dificuldade na produção de mudas em programas de reflorestamento.

A dormência tegumentar caracteriza-se pela dificuldade de absorção de água pela semente, o que a impede de iniciar a hidratação e, conseqüentemente, restringe os processos físicos e as reações metabólicas básicas da germinação (BORGES et al., 2004). A impermeabilidade do tegumento pode ocorrer devido à presença de cutícula e de uma camada bem desenvolvida de células em paliçada, ou de ambas (COPELAND e McDONALD, 1995), o que impede a absorção de água e impõe restrição mecânica ao crescimento do embrião, retardando o processo de germinação. Sob condições naturais, esse tipo de dormência pode ser superado por processos de escarificação (MAYER e POLJAKOFFMAYBER, 1989), por ingestão pelos animais, pela atividade de microrganismos, pela acidez natural do solo e pelas queimadas (COPELAND e MCDONALD, 1995), os quais provocam a ruptura ou o enfraquecimento do tegumento, permitindo a entrada de água e gases e o início da germinação.

Em laboratório foram desenvolvidos diversos métodos, visando à superação da dormência por impedimento à entrada de água, como escarificações mecânica e química, embebição das sementes em água e tratamentos com altas temperaturas, sob condição úmida ou seca (PEREZ e PRADO, 1993). De acordo com Eira et al. (1993), todos esses tratamentos apresentaram vantagens e desvantagens, de modo que cada um deles deve ser estudado, levando-se em conta, também, o custo efetivo e sua praticidade de execução. Além disso, as sementes podem apresentar diferentes níveis de dormência, a exemplo das sementes de Medicago turbulenta, uma leguminosa do deserto, em que Koller (1972) verificou que a permeabilidade à água variava de $100 \%$ a $0 \%$, partindo da posição proximal em direção à distal. Em Xanthium strumarium, espécie que produz apenas duas sementes por fruto, uma, dita "superior", é profundamente dormente, e a outra, "inferior", não apresenta dormência alguma (ROBERTS, 1974). Assim, o método empregado deve ser efetivo na quebra da dormência, sem prejudicar as sementes com baixos níveis de dormência.

Entre os métodos utilizados para superação da dormência tegumentar, a escarificação mecânica é freqüentemente utilizada e constitui a opção mais prática e segura para pequenos agricultores (HERMANSEN et al., 2000), uma vez que é um método simples, de baixo custo e eficaz para promover germinação rápida e uniforme. Essa técnica é recomendada para pequenos lotes de sementes de Caesalpinea ferrea Mart. ex Tul. var. leiostachya Benth (LOPES et al., 1998), Peltophorum dubium (Sprengel) Taubert (PEREZ et al., 1999), Dimorphandra mollis Benth (HERMANSEN et al., 2000), Achras sapota L (AZERÊDO et al., 2002; MATOS et al., 2003), Schizolobium parahyba (Vell.) Blake (AZEREDO et al., 2003), Sterculia foetida L (SANTOS et al., 2004).

Outro método utilizado na superação da dormência de sementes que apresentam dormência tegumentar é a exposição a temperaturas elevadas (HARTMANN et al., 2002), o qual foi empregado com eficiência em sementes de Caesalpinea ferrea (LOPES et al., 1998), Acacia mearnsii De Willd (MARTINS-CORDER et al., 1999), Leucaena leucocephala (Lam.) de Wit (TELES et al., 2000), Pueraria lobata Willd (SUSKO et al., 2001), Peltophorum dubium (OLIVEIRA et al., 2003; PIROLI et al., 2005) e de Tachigalia multijuga Benth (BORGES et al., 2004).

Ainda com relação aos tratamentos para superação da dormência, o ácido sulfúrico tem sido utilizado com muita eficiência em sementes de Senna macranthera 
(Collad.) Irwin et Barn (ESCHIAPATI-FERREIRA e PEREZ, 1997), Leucaena diversifolia Schlecht (BERTALOT e NAKAGAWA, 1998), Guazuma ulmifolia Lam (ARAUJO NETO e AGUIAR, 2000), Copaifera langsdorfii Desf (BEZERRA et al., 2002), Bowdichia virgilioides Kunth (SMIDERLE e SOUZA, 2003), Ochroma lagopus Sw (BARBOSA et al., 2004) e de Peltophorum dubium (PIROLI et al., 2005).

Dessa forma e devido à dormência causada pela resistência do endocarpo, a absorção de água justificase a condução deste estudo, que teve como objetivo estabelecer métodos para acelerar e uniformizar a germinação de unidades de dispersão de Z. joazeiro.

\section{MATERIAL E MÉTODOS}

O trabalho foi realizado em casa de vegetação do Departamento de Fitotecnia do Centro de Ciências Agrárias da Universidade Federal da Paraíba, em Areia, PB. Os frutos deZ. joazeiro foram colhidos diretamente de árvoresmatrizes localizadas no Município de Barra de Santa Rosa, PB, em seguida levados para o Laboratório de Análise de Sementes, onde foram despolpados manualmente e submetidos à fermentação por cinco dias, para retirada de mucilagem. Decorrido esse período, as unidades de dispersão (endocarpo + semente) foram lavadas com água corrente, sob peneira de arame e postas para secar à sombra em ambiente de laboratório por cinco dias.

Os tratamentos utilizados para superação da dormência constaram de escarificação manual com lixa, imersão em água à temperatura ambiente por $24,48,72$, 96 e 120 h, imersão em água à temperatura de $70^{\circ} \mathrm{C}$ por 3 min e imersão em ácido sulfúrico concentrado por 30 , $60,90,120$ e $150 \mathrm{~min}$, sendo unidades de dispersão intactas usadas como testemunha. A escarificação mecânica foi realizada manualmente com lixa número 80 , no lado oposto ao da emergência da raiz primária até o rompimento do endocarpo. Nos tratamentos com água quente e fria, as unidades de dispersão foram imersas em um volume de água cinco vezes superior às elas. Nos tratamentos com ácido sulfúrico concentrado, as unidades de dispersão foram lavadas em água corrente, por $1 \mathrm{~h}$, após a submersão pelos períodos descritos anteriormente.

Depois de submetidas aos tratamentos, as unidades de dispersão foram semeadas a uma profundidade de $2 \mathrm{~cm}$, em bandejas plásticas perfuradas, entre areias previamente peneiradas e esterilizadas em autoclave, umedecidas com quantidade de água equivalente a $60 \%$ da capacidade de retenção. Avaliaram-se as seguintes características: emergência - utilizaram-se 100 unidades de dispersão por tratamento, divididas em quatro repetições de 25 . A contagem do número de plântulas emersas foi realizada aos 118 dias após a semeadura, cujo critério utilizado foi o de plântulas normais que apresentavam as estruturas essenciais perfeitas (BRASIL, 1992); primeira contagem de emergência correspondente à porcentagem acumulada de plântulas normais aos 26 dias após o início do teste em todos os tratamentos, com exceção da testemunha, cuja contagem foi realizada aos 54 dias, pelo fato de a emergência ser muito lenta; índice de velocidade de emergência (IVE) - foram realizadas contagens diárias das plântulas normais durante 118 dias e o índice, calculado conforme a fórmula proposta por Maguire (1962); comprimento da raiz principal e da parte aérea - no final do teste de emergência, a raiz principal e a parte aérea das plântulas normais de cada repetição foram medidas com o auxílio de régua graduada, sendo os resultados expressos em centímetro por plântula; massa seca das raízes e parte aérea - após a contagem final no teste de emergência, aos 118 dias após a semeadura separaram-se, com o auxílio de tesoura, as raízes e a parte aérea das plântulas anteriormente medidas, as quais mesmas foram submetidas à secagem em estufa regulada a $65^{\circ} \mathrm{C}$ até atingir peso constante.

O delineamento experimental utilizado foi o inteiramente ao acaso, com quatro repetições de 25 unidades de dispersão por tratamento, num total de 13. Os dados foram submetidos à análise de variância e as médias, comparadas pelo teste de Tukey a $5 \%$ de probabilidade.

\section{RESULTADOS E DISCUSSÃO}

De acordo com os dados apresentados na Tabela 1 , observa-se que a imersão das unidades de dispersão em água à temperatura ambiente por $48 \mathrm{~h}$, bem como a imersão em água à temperatura de $70 \mathrm{oC}$ por três min, proporcionaram os maiores porcentuais de emergência de plântulas sem diferir estatisticamente, das unidades de dispersão da testemunha (intactas). Esses resultados indicam que a imersão em água fria, como também em água quente, foi os tratamentos mais eficazes em superar a resistência mecânica imposta pelo endocarpo. Assim, a absorção de água pelas unidades de dispersão desencadeou o processo de germinação e posterior emergência das plântulas, evidenciando, dessa forma,

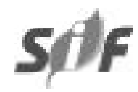

R. Árvore, Viçosa-MG, v.32, n.3, p.407-415, 2008 
que a resistência mecânica do endocarpo era o único impedimento à emergência.

Para sementes deDidymopanax morototoni(Aubl.) Dcne. et Planch, lavagens com água destilada e mistura de álcool + água por 45 min proporcionaram elevadas porcentagens de germinação (FRANCO e FERREIRA, 2002). Em sementes deAcacia mearnsii, Martins-Corder et al. (1999) obtiveram as maiores porcentagens de germinação com a imersão em água à temperatura de 80 oC por 1,3 e 5 min e escarificação com lixa. O tratamento de imersão das sementes de Peltophorum dubium em água a 95 oC também foi eficiente na promoção da germinação (OLIVEIRA et al., 2003).

Ainda com relação à emergência das plântulas, as menores porcentagens foram registradas nos tratamentos de escarificação mecânica com lixa, imersão em água fria por $120 \mathrm{~h}$, bem como imersão em ácido sulfúrico concentrado em todos os períodos utilizados (Tabela 1).

A escarificação química com ácido sulfúrico concentrado não produziu o efeito desejado, aumentando e acelerando a emergência das plântulas. As baixas porcentagens de emergência obtidas com as unidades de dispersão imersas no ácido sulfúrico concentrado indicam provável ocorrência de algum tipo de dano fisiológico nas estruturas internas das unidades de dispersão, pelo fato de a sua concentração ter sido excessiva. Hermansen et al. (2000) relataram que a imersão de sementes de Dimorphandra mollis em ácido sulfúrico concentrado por períodos superiores a 90 min resultaram em decréscimo marcante na viabilidade. EmZizyphus joazeiro, o pré-condicionamento das unidades de dispersão em ácido sulfúrico concentrado por períodos entre 74 e 115 min foi eficiente na uniformização da emergência de plântulas, porém a porcentagem total de plântulas emergidas foi inferior a 70\% (ALVES et al., 2006).

No caso deste estudo, as unidades de dispersão ficaram enegrecidas depois do referido tratamento, e a emergência das plântulas foi prejudicada, apesar de esse tipo de tratamento ter sido empregado com eficiência por vários pesquisadores para superação da dormência de diversas espécies que têm sementes com tegumento impermeável à água, a exemplo de Parkia multijuga (BIANCHETTI et al., 1998), Guazuma ulmifolia (ARAUJO NETO e AGUIAR, 2000), Leucaena leucocephala (TELES et al., 2000), Dimorphandra mollis (HERMANSEN et al., 2000), Enterolobium contortisiliquum(MENEGHELLO et al., 2000) eSatureja montana (BOSCAGLI e SETTE, 2001), entre outras.

Os valores médios referentes ao vigor, determinado pela primeira contagem de emergência, são apresentados na Tabela 1, através dos quais se observa que a escarificação mecânica com lixa d'água e imersão em ácido sulfúrico por 90, 120 e 150 min foram responsáveis pelo maior vigor das unidades de dispersão, no entanto não diferiram estatisticamente da imersão em ácido sulfúrico por $60 \mathrm{~min}$.

Quadro 1 - Emergência de plântulas e vigor de sementes (primeira contagem e índice de velocidade de emergência - IVE) de Z. joazeiro, oriundas de unidades de dispersão submetidas a diferentes tratamentos para superação da dormência Table 1 - Seedling emergence and vigor (first count and emergence speed index-IVE) of Z. joazeiro seeds derived from dispersal units subjected to different treatments for dormancy breaking

\begin{tabular}{|c|c|c|c|}
\hline Tratamentos & Emergência (\%) & Primeira Contagem $(\%)$ & IVE \\
\hline Testemunha & $89 \mathrm{ab}$ & $5 \mathrm{~d}$ & $0,25 \mathrm{c}$ \\
\hline Escarificação com lixa & 76 cdef & $60 \mathrm{a}$ & $0,67 \mathrm{a}$ \\
\hline Imersão em água fria/24 h & $80 \mathrm{bcd}$ & $4 \mathrm{~d}$ & $0,25 \mathrm{c}$ \\
\hline Imersão em água fria/48 h & $97 \mathrm{a}$ & $4 \mathrm{~d}$ & $0,28 \mathrm{c}$ \\
\hline Imersão em água fria/72 h & $83 \mathrm{bc}$ & $5 \mathrm{~d}$ & $0,26 \mathrm{c}$ \\
\hline Imersão em água fria/96 h & 79 bcde & $23 \mathrm{c}$ & $0,33 \mathrm{c}$ \\
\hline Imersão em água fria/ $120 \mathrm{~h}$ & 75 cdefg & $27 \mathrm{c}$ & $0,29 \mathrm{c}$ \\
\hline Imersão em água a $70^{\circ} \mathrm{C} / 3 \mathrm{~min}$ & $100 \mathrm{a}$ & $4 \mathrm{~d}$ & $0,26 \mathrm{c}$ \\
\hline Imersão em $\mathrm{H}_{2} \mathrm{SO}_{4} / 30 \mathrm{~min}$ & $65 \mathrm{fgh}$ & $37 \mathrm{bc}$ & $0,32 \mathrm{c}$ \\
\hline Imersão em $\mathrm{H}_{2} \mathrm{SO}_{4} / 60 \mathrm{~min}$ & 69 defg & $51 \mathrm{ab}$ & $0,48 \mathrm{c}$ \\
\hline Imersão em $\mathrm{H}_{2} \mathrm{SO}_{4} / 90 \mathrm{~min}$ & 67 efg & $53 \mathrm{a}$ & $0,47 \mathrm{~b}$ \\
\hline Imersão em $\mathrm{H}_{2} \mathrm{SO}_{4} / 120$ min & $63 \mathrm{gh}$ & $56 \mathrm{a}$ & $0,45 \mathrm{~b}$ \\
\hline Imersão em $\mathrm{H}_{2} \mathrm{SO}_{4} / 150 \mathrm{~min}$ & $53 \mathrm{~h}$ & $52 \mathrm{a}$ & $0,44 \mathrm{~b}$ \\
\hline Valor de F & $27,57^{\text {*** }}$ & $62,92 * *$ & $34,40^{* *}$ \\
\hline DMS & 12,87 & 14,54 & 0,11 \\
\hline $\mathrm{CV}(\%)$ & 6,74 & $19,88$. & 11,69 \\
\hline
\end{tabular}


Apesar de ser um tratamento muito eficaz, a escarificação manual com lixa apresenta o inconveniente de sua aplicação prática pela dificuldade de execução em larga escala. Além disso, os tegumentos tendem a permanecer presos aos cotilédones das plântulas. Constatou-se que o desprendimento dos cotilédones é um importante fator no desenvolvimento de plântulas normais (OLIVEIRA et al., 2003). Assim, os métodos que utilizam água quente e fria foram superiores aos demais, levando-se em conta a eficiência e praticidade.

Diante desses resultados, constata-se que o ácido sulfúrico foi eficiente apenas em uniformizar a emergência das plântulas em razão, provavelmente, de algum tipo de dano que reduziu a sua porcentagem final, enquanto a escarificação mecânica, mostrou efetiva em aumentar e uniformizar a emergência das plântulas. A escarificação mecânica provoca fissuras no tegumento das sementes aumenta a sua permeabilidade, permitindo a embebição e a aceleração do início do processo de germinação (FRANKEe BASEGGIO, 1998). O tratamento de imersão das unidades de dispersão de Zizyphus joazeiro no ácido sulfúrico concentrado por $110 \mathrm{~min}$ proporcionou uma porcentagem média de emergência de $50 \%$ por ocasião da primeira contagem (ALVES et al., 2006).

Apesar dos resultados observados com o uso do ácido sulfúrico concentrado, a metodologia de superação da dormência de sementes de uma espécie deve ser determinada, levando-se em conta, também, a sua praticidade e o seu custo. O uso de ácido sulfúrico apresenta riscos como queimaduras e necessidade de um local apropriado para o seu descarte, além da dificuldade de empregá-lo em larga escala, devido aos cuidados necessários à sua aplicação e ao custo.

Os dados referentes ao índice de velocidade de emergência encontram-se na Tabela 1, em que se observa que a escarificação mecânica com lixa proporcionou emergência mais rápida e uniforme, seguida pela imersão emácido sulfúrico por 90, 120 e 150 min. De forma semelhante ao que ocorreu com a porcentagem e a primeira contagem de emergência, o tratamento de escarificação mecânica demonstrou que esse foi realmente eficiente na superação da resistência mecânica do endocarpo e emergência das plântulas. Em sementes de Acacia mearnsii, MartinsCorder et al. (1999) também obtiveram os maiores valores de velocidade de germinação quando utilizaram escarificação mecânica com lixa nos 100, 120 e 150. Alves et al. (2006) também constataram que o tratamento de imersão das unidades de dispersão de Zizyphus joazeiro no ácido sulfúrico concentrado por 100 min foi responsável pelo maior índice de velocidade de emergência $(0,51)$.
Em sementes de Cassia excelsa Scharad (JELLER e PEREZ, 1999) e de Peltophorum dubium (PEREZ et al., 1999) a imersão em água fervente por 5 e 10 min proporcionou baixos índices de velocidade de germinação. Para sementes de Bauhinia monandra e de Bauhinia ungulata (ALVES et al., 2000), a imersão em água à temperatura de $80^{\circ} \mathrm{C}$ até o resfriamento também resultou em menores índices de velocidade de germinação.

Os menores valores de velocidade de germinação de sementes de Mimosa caesalpiniaefolia Benth foram obtidos com o tratamento de imersão em água fervente por 2 min, o qual se igualou á testemunha: sementes intactas (BRUNO et al., 2001). No entanto, em sementes deMimosa bimucronata (RIBAS et al., 1996) e deAcacia mearnsii (ROVERSI et al., 2002), a imersão das sementes em água, às temperaturas de 80 e $90^{\circ} \mathrm{C}$, respectivamente, proporcionaram os maiores índices de velocidade de germinação.

Quanto ao comprimento da raiz primária (Tabela 2), as plântulas oriundas de unidades de dispersão intactas, bem como daquelas submetidas à escarificação mecânica com lixa d'água, imersão em água à temperatura ambiente por $24,48,72 \mathrm{~h}$ e imersão em água à temperatura de 70 ${ }^{\circ} \mathrm{C}$ por $3 \mathrm{~min}$, demonstraram os menores valores. Com relação ao comprimento da parte aérea (Tabela 2), as plântulas originadas das unidades de dispersão intactas apresentaram médias menores, sem diferenças estatísticas daquelas oriundas do tratamento de imersão em água a $70^{\circ} \mathrm{C}$, por $3 \mathrm{~min}$. Já Oliveira et al. (2002) obtiveram maior comprimento de plântulas de Platonia insignis, quando estas foram oriundas de sementes submetidas aos tratamentos relativos à remoção da película, dois e três cortes, com e sem imersão em água morna ( $\left.40^{\circ} \mathrm{C} / 20 \mathrm{~min}\right)$.

Diante dos resultados, observou-se que o comprimento das plântulas não foi uma característica muito afetada pelos tratamentos pré-germinativos empregados, uma vez que aqueles que proporcionaram emergência mais rápida e uniforme resultaram, algumas vezes, em plântulas com menor comprimento. Percebeuse, dessa forma, que os tratamentos empregados para superação da dormência das unidades de dispersão do $Z$. joazeiro não interferiram, de forma significativa, no desenvolvimento das plântulas que conseguiram emergir. Resultados diferentes foram obtidos por Alves et al. (2006), quando observaram que os maiores valores de comprimento de plântulas $(26,85 \mathrm{~cm})$ deZizyphus joazeiro foram obtidos quando as unidades de dispersão foram imersas no ácido sulfúrico concentrado por $95 \mathrm{~min}$.

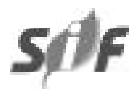

R. Árvore, Viçosa-MG, v.32, n.3, p.407-415, 2008 
Quadro 2 - Vigor de sementes (comprimento da raiz primária e parte aérea) de Z. joazeiro, oriundas de unidades de dispersão submetidas a diferentes tratamentos para superação da dormência

Table 2 - Seed vigor (length of primary root and aerial part) of Z. joazeiro derived from dispersal units subjected to different treatments for dormancy breaking

\begin{tabular}{lcc}
\hline \multicolumn{1}{c}{ Tratamentos } & \multicolumn{2}{c}{ Comprimento (cm/plântula) } \\
\cline { 2 - 3 } & Raiz Primária & Parte Aérea \\
\hline Testemunha & $8,01 \mathrm{~d}$ & $6,63 \mathrm{~d}$ \\
Escarificação com lixa & $8,21 \mathrm{~d}$ & $12,41 \mathrm{a}$ \\
Imersão em água fria/24 h & $7,71 \mathrm{~d}$ & $13,02 \mathrm{a}$ \\
Imersão em água fria/48 h & $8,06 \mathrm{~d}$ & $12,75 \mathrm{a}$ \\
Imersão em água fria/72 h & $8,20 \mathrm{~d}$ & $12,59 \mathrm{a}$ \\
Imersão em água fria/96 h & $15,74 \mathrm{a}$ & $10,72 \mathrm{abc}$ \\
Imersão em água fria/120 h & $14,54 \mathrm{ab}$ & $9,96 \mathrm{bc}$ \\
Imersão em água a $70{ }^{\circ} \mathrm{C} / 3 \mathrm{~min}$ & $7,99 \mathrm{~d}$ & $8,44 \mathrm{~cd}$ \\
Imersão em $\mathrm{H}_{2} \mathrm{SO}_{4} / 30 \mathrm{~min}$ & $14,89 \mathrm{ab}$ & $11,07 \mathrm{ab}$ \\
Imersão em $\mathrm{H}_{2} \mathrm{SO}_{4} / 60 \mathrm{~min}$ & $14,46 \mathrm{ab}$ & $11,50 \mathrm{ab}$ \\
Imersão em $\mathrm{H}_{2} \mathrm{SO}_{4} / 90 \mathrm{~min}$ & $14,28 \mathrm{ab}$ & $11,47 \mathrm{ab}$ \\
Imersão em $\mathrm{H}_{2} \mathrm{SO}_{4} / 120 \mathrm{~min}$ & $13,75 \mathrm{bc}$ & $11,42 \mathrm{ab}$ \\
Imersão em $\mathrm{H}_{2} \mathrm{SO}_{4} / 150 \mathrm{~min}$ & $12,33 \mathrm{c}$ & $11,30 \mathrm{ab}$ \\
\hline Valor de $\mathrm{F}$ & $75,99 * *$ & $15,15^{* *}$ \\
DMS & 1,91 & 2,32 \\
CV (\%) & 6,71 & 8,43 \\
\hline
\end{tabular}

Médias seguidas de mesma letra não diferem estatisticamente entre si, pelo teste de Tukey a 5\%.

Resultados semelhantes foram obtidos por Alves et al. (2004), quando observaram que o comprimento de plântulas de $B$. divaricata não foi uma característica muito afetada pelos tratamentos pré-germinativos utilizados, em que os maiores valores foram obtidos com as plântulas oriundas das sementes submetidas ao tratamento desponte na região oposta à micrópila e da testemunha (sementes intactas). No entanto, para Acacia mangium (LIMA e GARCIA, 1996) eAcacia mearnsii(ROVERSI et al., 2002), os maiores valores de comprimento das plântulas foram obtidos quando estas foram originadas de sementes submetidas ao tratamento de imersão em água, às temperaturas de 80 e $90^{\circ} \mathrm{C}$, respectivamente.

Conforme dados da Tabela 3 , referentes à massa seca das raízes e da parte aérea, constatou-se que, quando as unidades de dispersão foram submetidas aos tratamentos de imersão em ácido sulfúrico concentrado por 120 e 150 min, originaram plântulas mais vigoras, ou seja, com maior conteúdo de massa seca nas raízes e na parte aérea. Provavelmente, esses resultados se devem ao fato de as unidades de dispersão dos referidos tratamentos terem proporcionado uma emergência das plântulas mais rápida e, assim, terem acumulado maior fitomassa, uma vez que os cotilédones são foliáceos e, por ocasião da emergência, passam a realizar fotossíntese. De forma semelhante, Alves et al. (2006) obtiveram os maiores valores de massa de plântulas (4,27 g) de Zizyphus joazeiro, quando as unidades de dispersão foram imersas no ácido sulfúrico concentrado por $97 \mathrm{~min}$.

Em Bauhinia divaricata, os maiores valores de massa seca das plântulas foram obtidos com sementes submetidas aos tratamentos de desponte na região oposta à micrópila e imersão em água às temperaturas de 60 e $70^{\circ} \mathrm{C}$ (ALVES et al., 2004). Entretanto, com sementes de Mimosa caesalpiniaefolia foi observado que a imersão em água fervente por 2 min proporcionou menor conteúdo de massa seca nas plântulas (BRUNO et al., 2001).

\section{CONCLUSÃO}

- A escarificação química com ácido sulfúrico concentrado não é eficiente para a superação da resistência mecânica dos endocarpos de Z. joazeiro.

- A imersão em água quente, bem como em água fria, proporciona uma elevada emergência de plântulas, porém desuniforme.

- O tratamento de escarificação manual com lixa propicia as melhores porcentagens e uniformidades de emergênciade plântulas. 
Quadro 3 - Vigor de sementes (massa seca da raiz primária e parte aérea) de Z. joazeiro, oriundas de unidades de dispersão submetidas a diferentes tratamentos para superação da dormência

Table 3 - Seed vigor (dry mass of primary root and aerial part) of Z. joazeiro derived from dispersal units subjected to different treatments for dormancy breaking

\begin{tabular}{|c|c|c|}
\hline \multirow{2}{*}{ Tratamentos } & \multicolumn{2}{|c|}{ Massa seca (g/plântula) } \\
\hline & Raízes & Parte Aérea \\
\hline Testemunha & $0,009 \mathrm{e}$ & $0,064 \mathrm{e}$ \\
\hline Escarificação com lixa & $0,039 \mathrm{bc}$ & $0,116 \mathrm{~d}$ \\
\hline Imersão em água fria/24 h & $0,015 \mathrm{e}$ & $0,065 \mathrm{e}$ \\
\hline Imersão em água fria/48 h & $0,017 \mathrm{e}$ & $0,078 \mathrm{e}$ \\
\hline Imersão em água fria/72 h & $0,020 \mathrm{de}$ & $0,078 \mathrm{e}$ \\
\hline Imersão em água fria/96 h & $0,036 \mathrm{c}$ & $0,146 \mathrm{bc}$ \\
\hline Imersão em água fria/120 h & $0,031 \mathrm{~cd}$ & $0,137 \mathrm{bcd}$ \\
\hline Imersão em água a $70^{\circ} \mathrm{C} / 3 \mathrm{~min}$ & $0,010 \mathrm{e}$ & $0,067 \mathrm{e}$ \\
\hline Imersão em $\mathrm{H}_{2} \mathrm{SO}_{4} / 30 \mathrm{~min}$ & $0,033 \mathrm{c}$ & $0,135 \mathrm{~cd}$ \\
\hline Imersão em $\mathrm{H}_{2} \mathrm{SO}_{4} / 60 \mathrm{~min}$ & $0,036 \mathrm{c}$ & $0,159 \mathrm{~b}$ \\
\hline Imersão em $\mathrm{H}_{2} \mathrm{SO}_{4} / 90 \mathrm{~min}$ & $0,036 \mathrm{c}$ & $0,160 \mathrm{~b}$ \\
\hline Imersão em $\mathrm{H}_{2} \mathrm{SO}_{4} / 120 \mathrm{~min}$ & $0,053 \mathrm{a}$ & $0,193 \mathrm{a}$ \\
\hline Imersão em $\mathrm{H}_{2} \mathrm{SO}_{4} / 150 \mathrm{~min}$ & $0,050 \mathrm{ab}$ & $0,185 \mathrm{a}$ \\
\hline Valor de F & $34,86 * *$ & $105,46^{* *}$ \\
\hline DMS & 0,01 & 0,02 \\
\hline $\mathrm{CV}(\%)$ & 16,32 & 7,51 \\
\hline
\end{tabular}

Médias seguidas de mesma letra não diferem estatisticamente entre si, pelo teste de Tukey a $5 \%$.

\section{REFERÊNCIAS}

ALVES, A. U. et al. Ácido sulfúrico na superação da dormência de unidades de dispersão de juazeiro (Zizyphus joazeiro Mart.). Revista Árvore, v.30, n.2, p.187-195, 2006.

ALVES, A. U. et al. Superação da dormência em sementes de Bauhinia divaricata L. Acta Botanica Brasilica, v.18, n.4, p.871-879, 2004.

ALVES, M. C. S. et al. Superação da dormência em sementes de Bauhinia monandra Britt e Bauhinia ungulata L. - Caesalpinoideae. Revista Brasileira de Sementes, v.22, n.2, p.139-144, 2000.

ARAÚJO NETO, J. C.; AGUIAR, I. B. Tratamentos pré-germinativos para superar a dormência de sementes de Guazuma ulmifolia Lam. Scientia Forestalis, n.58, p.15-24, 2000.

AZERÊDO, G. A. et al. Desempenho de sementes de sapoti (Achras sapotaL.) submetidas a diferentes tratamentos pré-germinativos. Revista Brasileira de Fruticultura, v.24, n.1, p.147-150, 2002.

AZEREDO, G. A. et al. Germinação em sementes de espécies florestais da mata atlântica (Leguminoseae) sob condições de casa de vegetação. Pesquisa Agropecuária Tropical, v.33, n.1, p.11-16, 2003.
BARBOSA, A. P. et al. Tecnologia alternativa para a quebra de dormência das sementes de pau-debalsa (Ochroma lagopus Sw., Bombacaceae). Acta Amazonica, v.34, n.1, p.107-110, 2004.

BERTALOT, M. J.A.; NAKAGAWA, J. Superação da dormência em sementes de Leucaena diversifolia (Schlecht.) Bentham K 1561. Revista Brasileira de Sementes, v.20, n.1, p.39-42, 1998.

BEZERRA, A. M. C. et al. Germinação e desenvolvimento de plântulas de copaíba em função do tamanho e da imersão da semente em ácido sulfúrico. Revista Ciência Agronômica, v.33, n.2, p.5-12, 2002.

BIANCHETTI, A. et al. Escarificação ácida para superar a dormência de sementes de pinho-cuiabano (Parkia multijuga Benth.). Revista Brasileira de Sementes, v.20, n.1, p.215-218, 1998.

BORGES, E. E. L. et al. Alterações fisiológicas em sementes de Tachigalia multijuga (Benth.) (mamoneira) relacionadas aos métodos para a superação da dormência. Revista Árvore, v28, n.3, p.317-325, 2004.

BOSCAGLI, A.; SETTE, B. Seed germination enhancement in Satureja Montana L. spp. Montana. Seed Science and Technology, v.29, n.2, p.347-355, 2001.

R. Árvore, Viçosa-MG, v.32, n.3, p.407-415, 2008 
BRASIL. Ministério da Agricultura e Reforma Agrária. Regras para análise de sementes. Brasília: SNDA/DNDV/CLAV, 1992. 365p.

BRUNO, R.L.A. et al. Tratamentos prégerminativos para superar a dormência de sementes de Mimosa caesalpiniaefolia Benth.

Revista Brasileira de Sementes, v.23, n.2, p.136-143, 2001.

CARVAlho, N. M.; NAKAGAWA, J. Sementes: ciência, tecnologia e produção. Jaboticabal: FUNEP, 2000. 429p.

COPELAND, L. O.; MCDONALD, M. B. Principles of seed science and technology. New York: Chapmam \& Hall, 1995. 409p.

EIRA, M. T. S. et al. Superação da dormência de sementes de Enterolobium contortisiliquum (Vell.) Morong. Leguminosae. Revista Brasileira de Sementes, v.15, n.2, p.177-182, 1993.

ESCHIAPATI-FERREIRA, M. S.; PEREZ, S. C. J. G. A. Tratamentos para superar a dormência de sementes de Senna macranthera (Collad.) Irwin et Barn. (Fabaceae - Caesalpinoideae).

Revista Brasileira de Sementes, v.19, n.2, p.230-236, 1997.

FRANCO, E. T. H.; FERREIRA, A. G. Tratamentos pré-germinativos em sementes de Didymopanax morototoni (Aubl.) Dcne. et Planch. Ciência Florestal, v.12, n.1, p.1-10, 2002.

FRANKE, L. B.; BASEGGIO, J. Superação da dormência de sementes de Desmodium incanum DC. e Lathyrus nervosus Lam.

Revista Brasileira de Sementes, v.20, n.2, p.182-186, 1998.

HARTMANN, H. T. et al. Plant propagation: Principles and practices. 7.ed. New Jersey: Prentice-Hall, 2002. 896p.

HERMANSEN, L. A. et al. Pretreatments to overcome seed coat dormancy in Dimorphandra mollis Benth. Seed Science and

Technology, v.28, n.3, p.581-595, 2000.

R. Árvore, Viçosa-MG, v.32, n.3, p.407-415, 2008
JELLER, H.; PEREZ, S. C. J. G A. Estudo da superação da dormência e da temperatura em sementes deCassia excelsa Schrad. Revista Brasileira de

Sementes, v.21, n.1, p.32-40, 1999.

KOLLER, D. Environmental control of seed germination. In: KOZLOWSKI, T. T. (Ed.) Seed biology. New York: Academic Press, 1972. p.2-93.

LIMA, D.; GARCIA, L. C. Avaliação de métodos para o teste de germinação em sementes de Acacia mangium Willd. Revista Brasileira de Sementes, v.18, n.2, p.180-185, 1996.

LOPES, J. C. et al. Germinação de sementes de espécies florestais de Caesalpinea ferrea, Cassia grandis L. e Samanea saman Merrill, após tratamentos para superar a dormência. Revista Brasileira de Sementes, v.20, n.1, p.80-86, 1998.

LORENZI, H. Árvores brasileiras : manual de identificação e cultivo de plantas arbóreas nativas do Brasil. 2.ed. Nova Odessa: Instituto Plantarum, 2002. 368p.

MAGUIRE, J. D. Speed of germination aid in selection and evaluation for seedling emergence and vigor. Crop Science, v.2, n.2, p.176-177, 1962 .

MARTINS-CORDER, M. P. et al. Fotoperiodismo e quebra de dormência em sementes de acácia-negra (Acacia mearnsii De Willd.). Ciência

Florestal, v.9, n.1, p.71-77, 1999.

MATOS F. J. A. Plantas medicinais: guia de seleção e emprego de plantas usadas em fitoterapia no Nordeste do Brasil. 2.ed. Fortaleza: Universidade Federal do Ceará, 2000. 346p.

MATOS, V. P. et al. Sementes de sapoti (Achras sapota L.): dormência e emergência. Pesquisa Agropecuária Tropical, v.33, n.2, p.79-82, 2003.

MAYER, A. M.; POLJAKOFF-MAYBER, A. The germination of seeds. New York: Pergamon Press, 1989. 270p. 
MENDES, B. V. Juazeiro (Zizyphus joazeiro Mart.): símbolo da resistência das plantas das caatingas. Mossoró: Fundação Vingt-Un Rosado/ETFERN-UNED, 1996. 24p. (Coleção Mossoroense, 168).

MENEGHELLO, G. E. et al. Tratamentos para superar a dormência de sementes de Enterolobium contortisiliquum (Vel.) Morong. Agropecuária Clima Temperado, v.3, n.2, p.199-204, 2000.

OLIVEIRA, F. C. et al. Métodos para acelerar a germinação de sementes de bacuri (Platonia insignis Mart.). Revista Brasileira de Fruticultura, v.24, n.1, p.51-154, 2002.

OLIVEIRA, L. M. et al. Avaliação de métodos para quebra da dormência e para a desinfestação de sementes de canafístula (Peltophorum dubium (Sprengel) Taubert). Revista Árvore, v.27, n.5, p.597-603, 2003.

PEREZ, S. C. J. G.; PRADO, C. H. B. A. Efeitos de diferentes tratamentos pré-germinativos e da concentração de alumínio no processo germinativo de sementes de Copaifera langsdorffii Desf. Revista Brasileira de Sementes, v.15, n.1, p.115-118, 1993.

PEREZ, S. C. J. G. A. et al. Dormancy break and light quality effects on seed germination of Peltophorum dubium Taub. Revista Árvore, v.23, n.2, p.131-137, 1999.

PIROLI, E. L. et al. Germinação de sementes de canafístula Peltophorum dubium (Spreng.) Taub. tratadas para superação da dormência.

Colloquium Agrariae, v.1, n.1, p.13-18, 2005.
PRADO, D. E.; GIBBS, P. E. Patterns of species distribution in the dry seasonal forests of South America. Annals of Missouri Botanical Garden, v.80, n.4, p.902-927, 2003.

RIBAS, L. L. F. et al. Superação da dormência de sementes de Mimosa bimucronata (DC.) O.

Kuntze (maricá). Revista Brasileira de Sementes, v.18, n.1, p.98-101, 1996.

ROBERTS, E. H. Dormancy: A factor affecting seed survival in the soil. In: ROBERTS, E. H. (Ed.). Viability of seeds. London: Chapman and Hall, 1974. p.321-359.

ROVERSI, T. et al. Superação da dormência em sementes de acácia negra (Acacia mearnsii Willd.). Revista Brasileira de Agrociência, v.8, n.2, p.161-163, 2002.

SANTOS, T. O. et al. Escarificação mecânica em sementes de chichá (Sterculia foetida L.).

Revista Árvore, v.28, n.1, p.1-6, 2004.

SMIDERLE, O. J.; SOUSA, R. C. P. Dormência em sementes de paricarana (Bowdichia virgilioides Kunth - Fabaceae - Papilionidae). Revista Brasileira de Sementes, v.25, n.1, p.72-75, 2003.

SUSKO, D. J. et al. An evaluation of methods for breaking seed dormancy in kudzu (Pueraria lobata). Canadian Journal of Botany, v.79, n.2, p.197-203, 2001.

TELES, M. M. et al. Métodos para quebra da dormência em sementes de leucena (Leucaena leucocephala (Lam.) de Wit. Revista Brasileira de Zootecnia, v.29, n.2, p.387-391, 2000. 